\title{
Atopic dermatitis. Interdisciplinary diagnostic and therapeutic recommendations of the Polish Dermatological Society, Polish Society of Allergology, Polish Pediatric Society and Polish Society of Family Medicine. Part II. Systemic treatment and new therapeutic methods
}

\author{
Roman J. Nowicki ${ }^{1}$, Magdalena Trzeciak ${ }^{1}$, Maciej Kaczmarski², Aleksandra Wilkowska ${ }^{1}$, Magdalena Czarnecka-Operacz ${ }^{3}$, \\ Cezary Kowalewski ${ }^{4}$, Lidia Rudnicka ${ }^{5}$, Marek Kulus ${ }^{6}$, Agnieszka Mastalerz-Migas ${ }^{7}$, Jarosław Peregud-Pogorzelski ${ }^{8}$, \\ Małgorzata Sokołowska-Wojdyło ${ }^{1}$, Radosław Śpiewak ${ }^{9}$, Zygmunt Adamski ${ }^{3}$, Joanna Czuwara ${ }^{5}$, Monika Kapińska-Mrowiecka ${ }^{10}$, \\ Andrzej Kaszuba ${ }^{11}$, Dorota Krasowska ${ }^{12}$, Beata Kręcisz ${ }^{13}$, Joanna Narbuttt ${ }^{11}$, Sławomir Majewski ${ }^{14}$, Adam Reich ${ }^{15}$, \\ Zbigniew Samochocki ${ }^{5}$, Jacek Szepietowski ${ }^{16}$, Katarzyna Woźniak ${ }^{4}$ \\ ${ }^{1}$ Department of Dermatology, Venereology, and Allergology, Medical University of Gdansk, Gdansk, Poland \\ 2Department of Paediatrics, Paediatric Gastroenterology and Allergology, Medical University of Bialystok, Bialystok, Poland \\ ${ }^{3}$ Department of Dermatology, Poznan University of Medical Sciences, Poznan, Poland \\ ${ }^{4}$ Department of Dermatology and Immunodermatology, Medical University of Warsaw, Warsaw, Poland \\ ${ }^{5}$ Department of Dermatology, Medical University of Warsaw, Warsaw, Poland \\ ${ }^{6}$ Department of Paediatric Pneumonology and Allergology, Medical University of Warsaw, Warsaw, Poland \\ ${ }^{7}$ Department of Family Medicine, Medical University of Wroclaw, Wroclaw, Poland \\ ${ }^{8}$ Department of Paediatrics and Paediatric Oncology, Pomeranian Medical University, Szczecin, Poland \\ ${ }^{9}$ Department of Experimental Dermatology and Cosmetology, Jagiellonian University Medical College, Krakow, Poland \\ ${ }^{10}$ Dermatology Ward, Stefan Żeromski Specialist Hospital, Krakow, Poland \\ ${ }^{11}$ Department of Dermatology, Paediatric and Oncological Dermatology, Medical University of Lodz, Lodz, Poland \\ ${ }^{12}$ Department of Dermatology, Venereology and Paediatric Dermatology, Medical University, Lublin, Poland \\ ${ }^{13}$ Department of Dermatology, Faculty of Medicine and Health Sciences, Jan Kochanowski University, Kielce, Poland \\ ${ }^{14}$ Department of Dermatology and Venereology, Medical University of Warsaw, Warsaw, Poland \\ ${ }^{15}$ Department of Dermatology, University of Rzeszow, Rzeszow, Poland \\ ${ }^{16}$ Department of Dermatology, Venereology and Allergology, Medical University of Wroclaw, Wroclaw, Poland
}

Adv Dermatol Allergol 2020; XXXVII (2): 129-134

DOI: https://doi.org/10.5114/ada.2020.94829

\begin{abstract}
The treatment goal in atopic dermatitis is eliminating clinical symptoms of the disease, preventing exacerbations and complications, as well as improving patients' quality of life. In cases of severe atopic dermatitis and lack of response it is recommended to introduce systemic therapy. Patients ofter require multi-specialist consultations, and occasionally hospitalization. It is not recommended to use acupuncture, acupressure, bioresonance, homeopathy, or Chinese herbs in the treatment of atopic dermatitis.
\end{abstract}

Key words: atopic dermatitis, immunosuppressive drugs, biological treatment, dupilumab, allergen-specific immunotherapy, probiotics, alternative therapy.

The article was published in the journal "Dermatology Review/Przegląd Dermatologiczny" 2019, 106, 475-485, DOI: https://doi.org/10.5114/dr.2019.89995.

Address for correspondence: Prof. Roman J. Nowicki MD, PhD, Department of Dermatology, Venereology, and Allergology, Medical University of Gdansk, 17 Smoluchowskiego St, 80-214 Gdansk, Poland, phone: +48 5858440 10, e-mail: rnowicki@gumed.edu.pl Received: 18.09.2019 accepted: 4.10.2019. 


\section{Introduction}

In cases of severe atopic dermatitis (AD) and lack of response to topical treatment, it is recommended to consider administration of the following: cyclosporine $A(C y A)$ or dupilumab, methotrexate (MTX), azathioprine (AZA), mycophenolate mofetil (MMF), glucocorticoids (GCS) [1-10].

Prior to administration of immunosuppressive treatment it is recommended to:

- confirm the diagnosis of AD;

- excluding:

- disease-exacerbating factors,

- possibility of infections,

- comorbidities,

- contact eczema.

Cyclosporine A (CyA) is recommended as the first-line drug in severe cases of chronic AD in adults. In children and youths its application should be considered only in severe AD cases by a physician with appropriate experience. Recommendations regarding the use of the drug in children are based on results of single cohort studies and individual randomized cohort studies (off-label recommendations) $[3,11,12]$. Cyclosporine A decreases inflammation, area of lesions, and pruritus intensity, as well as improves the quality of sleep. An initial recommended drug dose is $5 \mathrm{mg} / \mathrm{kg}$ body weight/day with a reduction of $0.5-1 \mathrm{mg} / \mathrm{kg}$ body weight/day every 2 weeks, when clinical efficacy has been reached. Beneficial effects of CyA include a decrease in pruritus and skin inflammation, and is observed already within 26 weeks of treatment introduction [3, 11, 12]. It is recommended to administer CyA in cycles that last 12 weeks on average. Discontinuation of the drug is associated with recurrence of skin lesions within several weeks since the discontinuation of the treatment, however, it is assessed that condition of patients' skin does not return to the same condition as before the CyA treatment $[11,12]$. Dose decrease should be considered with regard to clinical efficacy. In some cases it may be recommended to opt for a long-term treatment with the lowest clinically effective dose [3]. The drug may also be administered in a long-term continuous therapy. CyA treatment duration depends on the clinical efficacy and drug tolerance, however, the treatment should not exceed 2 years and must be accompanied with thorough monitoring of possible serious adverse reactions. Despite the fact that many patients tolerate a much longer than 2 years therapy with a low CyA dose, after 2 years of the CyA therapy is should be attempted to discontinue the treatment or change the drug to another one that is administered generally [3]. In some patients a so-called weekend therapy is effective; it allows for decreasing an accumulative dose. A close monitoring of patients is recommended. Frequent adverse reactions of CyA (e.g. nephrotoxicity, hypertension) speak against the long-term AD treatment with CyA, and 3-6-month intervals are suggested [3].
Despite unquestionable efficacy of CyA in AD treatment, the use of this drug is associated with the risk of serious adverse reactions. Most of the side effects appear during the therapy, and subside after the drug is discontinued. In order to prevent them or decrease the risk for their appearance, it is recommended to monitor the treatment closely. Patients taking the drug should undergo regular exams with regard to arterial pressure and nephritic parameters. The risk for nephrotoxic activity increases when the drug dose exceeds $5 \mathrm{mg} / \mathrm{kg}$ body weight/day, increased creatinine values are maintained, and in the elderly. Kidneys may be permanently damaged (tubulopathy, vasculopathy) in individuals who take CyA continually for over 2 years [12]. In short-term intermittent CyA therapy, renal dysfunction is usually transient. The risk for occurrence of nephrotoxic activity is lower in children than in adults. Less common adverse reactions occurring during CyA therapy include neurological symptoms, such as headache, convulsions, paraesthesia, as well as disorders of the gastrointestinal tract, infections, gingival hypertrophy, hypertrichosis, hyperlipidaemia, disorders in electrolyte levels, an increased risk for developing skin cancers and lymphoproliferative hyperplasia. Measurements of CyA blood concentration during the therapy with this drug is not required since CyA concentration correlated with efficacy and toxicity only in a slight degree.

Despite the lack of clinical proofs, it is recommended to discontinue CyA 2 weeks before planned vaccination, and start taking it again 4-6 weeks after the vaccination $[2,3]$. During the CyA therapy, an effective UV protection should be used.

Dupilumab is an IL-4/IL-13 receptor $\alpha$ antagonist and the first biological drug in the world registered for treatment of moderate and server $A D$, which is not adequately controlled by recommended topical treatment or when such treatment is not recommended.

Dupilumab may be used as the second-line treatment in severe $A D$ after the first failure of general therapy. The drug may be used with or without local glucocorticosteroids (GCs). Clinical studies confirmed its statistically significant clinical efficacy with regard to improvements in disease symptoms measured with the use of EASI (75\%) and IGA scoring systems, and an improvement with $\geq 4$ points of pruritus evaluation according to Numeric Rating Scale (NRS) as compare with the placebo control group. A decrease in sleep disorders, an improvement in quality of life, and good drug tolerance were confirmed. The most commonly observed adverse events included: local reaction after subcutaneous drug administration, and conjunctivitis. A high safety profile of the drug and lack of dose-dependent toxicity were presented. The drug is administered according to the following scheme: $600 \mathrm{mg}$ in two injections with $300 \mathrm{mg}$, and then $300 \mathrm{mg}$ subcutaneously every 2 weeks. There is available data that indicates its long-term efficacy and safety [13-15]. 
Oral glucocorticosteroids (GCS) are allowed for AD treatment with a limitation, mainly in adult patients, to the period of 1 week, in rigidly selected cases, and in disease exacerbation periods [2, 3]. An equivalent of $0.5 \mathrm{mg}$ of prednisone/kg body weight should not be exceeded [3]. In everyday practice (different from published clinical study results) the most common reasons for discontinuation of treatment involving oral GCs are: adverse reactions, lack of treatment efficacy, lack of patient's co-operation, or abandonment of treatment by the patient after improvements in clinical condition have been achieved. During 10-year observational studies of AD-patients in the Netherlands, the lowest number of adverse reactions was noted during the treatment of oral GCs (5\%), MMF (22\%), and CyA (24\%). More adverse reactions were observed after the treatment with AZA (38\%) and MTX (41\%) - these adverse reactions regarded the gastrointestinal track in most cases. Then, the treatment was not effective in $15 \%$ of CyA and AZA cases, $20 \%$ of oral GCS cases, $44 \%$ of MMF cases, and $65 \%$ of MTX cases [16].

Methotrexate, AZA, and MMF may be used off-label in AD-patients if CyA is ineffective or there exist contraindications for its use [3].

Methotrexate (MTX) is recommended for treatment of severe $A D$ cases resistant to other treatment methods. It is highlighted that it is the second, after CyA, most frequently used drug in treatment of severe AD. Referenced literature included a number of reports on safety and efficacy of MTX in AD. The studies most often regard adults. There are also single reports on efficacy and safety of MTX usage in children [16-19].

Currently MTX is recommended in AD treatment in adults in doses similar to the ones used in treatment of psoriasis, i.e. 10-20 mg/week. The drug may be used in one dose once a week, but it is more often used in three doses of 2.5-7.5 mg every $12 \mathrm{~h}$ once a week [17-19]. Other authors recommend to use MTX in the dose of 7.5-25 mg/ week in adults, and $0.2-0.7 \mathrm{mg} / \mathrm{kg} /$ week in children [17]. The treatment is usually tolerated well, but it should be remembered that severe adverse reactions may occur. It is believed that frequency and intensity of adverse reactions is associated with the dose. Adverse reactions were reported mainly after the use of large MTX doses. More common ones included: hepatotoxicity, bone marrow suppression, pneumonocirrhosis, and renal insufficiency. Methotrexate is teratogenic - women and men should use effective contraception during the treatment and, according to SPC, for 6 months after its discontinuation [16-19].

Azathioprine (AZA) is used off-label in treatment of severe atopic dermatitis cases in adults resistant to other treatment methods, i.e. when CyA is noneffective or contraindicated. AZA may be also used off label in children [3]. A precise mechanism of AZA in AD has not been fully examined. In vitro studies suggest that AZA exerts suppressive and toxic influence on Langerhans cells. It is emphasized that AZA is really effective in AD treatment, however, due to AZA's mechanism, therapeutic effects of the drug may be delayed. In some patients, full therapeutic effects are reached even after 12 weeks or later.

It is recommended to use AZA in the dose of 1-3 mg/kg body weight/day. Prior to commencement of the treatment, thiopurine methyl transferase (TPMT) activity should be determined, since this enzyme participates in metabolism of 6-mercaptopurine, and in individuals with a congenital insufficiency of this enzyme, an increased myelosuppression may occur [3]. Thiopurine methyl transferase gene mutations may influence the efficacy and safety of treatment with AZA. Measuring the TPMT level allows for adjusting an individual dose to the patient, and decreasing the risk of bone marrow damage [20-26]. Individual authors used the drugs in severe AD in children and showed that it was effective. Toxic influence exerted on the bone marrow was not observed $[24,25]$. Furthermore, it was showed that AZA not only improves the clinical conditions, but also decreases the level of total lgE in children and youths with AD [26].

Azathioprine shows a number of adverse reactions. The most commonly observed include bone marrow damage and disorders of the immune system. Moreover, the following are also observed: vascular disorders (vasculitis), gastrointestinal disorders (nausea, emesis), and disorders involving the liver. Therefore, it is necessary to monitor transaminases and complete blood count during the treatment. According to the summary of product characteristics, within first 8 weeks of treatment, complete blood count examination should be performed once a week. During a later treatment period, the frequency of tests may be decreased to one test per month, and then, to one test per 3 months. In case the level of leucocytes or blood platelets drops below the normal limit, and in case other adverse reactions occur, the drug dose should be lowered.

While using AZA, patients should not be vaccinated with vaccines containing live microorganisms. Since AZA exhibits teratogenic activity, it should not be used during pregnancy. Furthermore, the drug should not be used during breastfeeding period. Azathioprine should not be combined with UV - an effective protection against UV should be used [3, 26].

Mycophenolate mofetil may be used off label in treatment of adults with $A D$ in the dose of up to $3 \mathrm{~g} /$ day if CyA is ineffective or contraindicated. Mycophenolate mofetil may be used in treatment of children and youths with AD. Mycophenolate mofetil is teratogenic - men and women must use effective contraception [3].

\section{Antihistamines}

There is no sufficient proof to use first- and secondgeneration antihistamines for treating pruritus in AD. First-generation antihistamines may inhibit histamine 
activity in subcortical regions of the central nervous system, and simultaneously exert anti-pruritic and sedative influence, what may be beneficial in case of patients with $A D$, who have problems with falling asleep and suffer from sleep disorders. Second-generation antihistamines are especially useful in patient with $A D$ that is accompanied by conjunctivitis or allergic rhinitis [3]. A higher specificity of the bond to histamine receptor $\mathrm{H} 1$, a longer halflife period, and hydrophilic structure of second-generation antihistamines contributed to an increased efficacy and safety of use of second-generation antihistamines [7, 27].

\section{Allergen-specific immunotherapy}

Allergen-specific immunotherapy is the only causal treatment for AD-patients. Indications for allergen-specific immunotherapy in AD-patients include cases with insufficient response to existing treatment and documented allergy to IgE-dependent airborne allergens [3, 28-31]. Allergen-specific immunotherapy for AD shows considerable clinical efficacy in treatment of patients with signs of being allergic to both year-round and seasonal airborne allergens, especially in patients allergic to one allergen group [3, 31]. So far, clinical effects with the use of allergen-specific immunotherapy in patients allergic to dust mites and pollens have been documented best [30, 31]. There are no contraindications to deallergize patients with AD or concomitant other atopic diseases, such as allergic rhinitis or mild bronchial asthma [3, 31]. Effective allergen-specific immunotherapy depends on proper patient qualification, proper choice of the vaccine composition, and proper execution of the therapy. Vaccine composition should be based on results of a detailed physical examination, interview, and reliable diagnostics based on skin prick tests and measurement of serum aslgE. Proper choice of vaccine composition, and the order of their administration in cases of patients suffering from $A D$ with polyvalent allergies determined the success of allergen-specific immunotherapy. While planning the therapy for AD-patients, allergological diagnostics should not be limited to skin prick tests, but should be supplemented with measurement of aslgE levels for proper allergens by means of brand new diagnostic methods, e.g. component-resolved [29-31].

Adverse reactions occur mainly during an induction phase of the allergen-specific immunotherapy, and are of mild as well as transient nature. Most often they take a form of erythema and skin oedema at site when the vaccine was administered. Systemic reactions are less common and occur as focal reactions distant from the allergen administration site, or there are general symptoms. Exacerbations of rhinitis or asthma as well as occurrence of skin pruritus and urticaria are observed. Non-specific symptoms, such as increased temperature, headaches, dizziness, fatigue, and muscle tiredness, are less frequently reported. Individual cases can involve a drop in arterial blood pressure, laryngeal oedema, or even anaphylactic shock. Usually, adverse reactions of allergen-specific immunotherapy are mild as well as transient, and include, first and foremost, the skin. However, while using allergen-specific immunotherapy, one should always be prepared for a pharmacological intervention and have anaesthesiologic protection [31]. This therapy should be conducted systematically for at least 45 years by an expert physician, with satisfaction of safety requirements, and allowing for occurrence of adverse reactions [30, 31].

\section{Probiotics}

Probiotics were examined with regard to possible application in AD treatment. A justification of the use of probiotics is that bacteria they contain induce immunological response type Th1 instead of Th2, what is to inhibit production development of IgE antibodies. Some reports show an enormous benefit associated with the use of probiotics in AD prevention and treatment. These studies show inconsistent results and require to be confirmed [32-36].

\section{Alternative treatment}

Balneotherapy with thermal water may be taken into consideration in treatment of mild and moderate AD. Cohort studies show that balneotherapy with thermal water with/without phototherapy may be effective in mild and moderate $\operatorname{AD}[3,37]$.

There is no proof of efficacy for acupuncture, acupressure, bioresonance, Chinese herbs, homeopathy, and massage/aromatherapy in the treatment of $A D$ [3]. Yet, a risk for developing a secondary contact allergy is observed after e.g. application of lavender oil that contains up to $40 \%$ of linalool $[38,39]$. Acupuncture, acupressure, bioresonance, homeopathy, and Chinese herbs are not recommended in AD treatment [3].

\section{New methods of therapy}

A phosphodiesterase 4 (PDE4) inhibitor for topical application in AD therapies that since 2016 has been available only in the US. In clinical studies including children above the age of 2 with mild and moderate $A D$, crisaborole was used twice a day for 4 weeks with the following results: a reduction of lesions on IGA scale was achieved, and pruritus was significantly reduced after 2 days of treatment. The studies lasted 48 weeks and confirmed efficacy and safety of crisaborole. Observed adverse reactions included pain, and infections at the sited of administration [40-42].

Currently, a number of new drugs for AD therapies are at the clinical study phase, including biological drugs, 
phosphodiesterase 4 (PDE4) antagonists, and protein kinase inhibitors (JAK) [43-46]. It appears that personalized/ individual medicine is the future of AD therapies. On the basis of measuring biomarkers specific for particular disease endotypes, it will be possible to qualify patients to proper therapeutic groups, and implement effective targeted treatment [47].

\section{Conclusions}

While treating AD-patients the following factors are of key importance: experience and close co-operation with patients and/or their families, education, prophylaxis, avoidance of factors exacerbating the disease, restoring dysfunctional skin barrier functions, containing pruritus, and elimination of inflammatory lesions as well as skin infections. The patients require frequent multispecialist consultations, and in serious cases, hospitalizations at wards dealing with treatments of this disease.

\section{Conflict of interest}

The authors declare no conflict of interest.

\section{References}

1. Wollenberg A, Oranje A, Deleuran M, et al. ETFAD/EADV Eczema task force 2015 position paper on diagnosis and treatment of atopic dermatitis in adult and paediatric patients. J Eur Acad Dermatol Venereol 2016; 30: 729-47.

2. Wollenberg A, Barbarot S, Bieber T, et al. Consensus-based European guidelines for treatment of atopic eczema (atopic dermatitis) in adults and children: part I. J Eur Acad Dermatol Venereol 2018; 32: 657-82.

3. Wollenberg A, Barbarot S, Bieber T, et al. Consensus-based European guidelines for treatment of atopic eczema (atopic dermatitis) in adults and children: part II. J Eur Acad Dermatol Venereol 2018; 32: 850-78.

4. Akdis CA, Akdis M, Bieber T, et al. Diagnosis and treatment of atopic dermatitis in children and adults. European Academy of Allergology and Clinical immunology/PRACTALL consensus report. Allergy 2006; 61: 969-87.

5. Hanifin JM, Cooper KD, Ho VC, et al. Guidelines of care for atopic dermatitis. J Am Acad Dermatol 2004; 50: 391-404.

6. Sidbury R, Davis DM, Cohen DE, et al. Guideline of care for the management of atopic dermatitis Section 3. Management and treatment with phototherapy and systemic agents. J Am Acad Dermatol 2014; 71: 327-49.

7. Johnson BB, Franco AI, Beck LA, Prezzano JC. Treatment-resistant atopic dermatitis: challenges and solutions. Clin Cosmet Investig Dermatol 2019; 12: 181-92.

8. Heller M, Shin HT, Orlow SJ, Schaffer JV. Mycophenolate mofetil for severe childhood atopic dermatitis: experience in 14 patients. Br J Dermatol 2007; 157: 127-32.

9. Simpson EL, Bruin-Weller M, Flohr C, et al. When does atopic dermatitis warrant systemic therapy? Recommendations from an expert panel of the International Eczema Council. J Am Acad Dermatol 2017; 77: 623-33.

10. Hoare C, Li Wan Po A, Williams H. Systematic review of treatments for atopic eczema. Health Technol Assess 2000; 4: $1-191$.
11. Harper J, Ahmed I, Barclay G, et al. Cyclosporin for severe childhood atopic dermatitis: short course versus continuous therapy. Br J Dermatol 2000; 142: 52-8.

12. Schmitt J, Schmitt N, Meurer M. Cyclosporin in the treatment of patients with atopic eczema - a systematic review and meta-analysis. J Eur Acad Dermatol Venereol 2007; 21: 606-19.

13. Simpson EL, Bieber T, Guttman-Yassky E, et al. Two phase 3 trials of dupilumab versus placebo in atopic dermatitis. N Engl J Med 2016; 375: 2335-48.

14. Blauvelt A, de Bruin-Weller M, Gooderham M, et al. Longterm management of moderate-to-severe atopic dermatitis with dupilumab and concomitant topical corticosteroids (LIBERTY AD CHRONOS): a 1-year, randomised, doubleblinded, placebo-controlled, phase 3 trial. Lancet 2017; 389: 2287-303.

15. de Bruin-Weller M, Thaci D, Smith CH, et al. Dupilumab with concomitant topical corticosteroid treatment in adults with atopic dermatitis with an inadequate response or intolerance to ciclosporin A or when this treatment is medically inadvisable: a placebo-controlled, randomized phase III clinical trial (LIBERTY AD CAFE). Br J Dermatol 2018; 178: 1083-101.

16. Garritsen FM, Roekevisch E, van der Schaft J, et al. Ten years experience with oral immunosuppressive treatment in adult patients with atopic dermatitis in two academic centres. J Eur Acad Dermatol Venereol 2015; 29: 1905-12.

17. El-Khalawany MA, Hassan H, Shaaban D, et al. Methotrexate versus cyclosporine in the treatment of severe atopic dermatitis in children; multicenterexperience from Egypt. Eur J Pediatr 2013; 172: 351-6.

18. Schramm ME, Roekevisch E, Leeflang MMG, et al. A randomized trial of methotrexate vs. azathioprine for severe atopic eczema. J Allergy Clin Immunol 2011; 128: 353-9.

19. Jenerowicz D, Silny W. Leczenie ogólne atopowego zapalenia skóry. In: Atopowe zapalenie skóry. Silny W (ed.). Termedia, Poznań 2012; 260-70.

20. Megitt SJ, Gray JC, Reynolds NI. Azathioprine dosed by thiopurine methyltransferase activit for moderate to severe atopic eczema: double blind, randomisswd, controlled trial. Lancet 2006; 367: 839-46.

21. Berth-Jones J, Takwale A, Tan E, et al. Azathioprine in severe adult atopic dermatitis: double- blind, placebo-controlled, crossover trial. Br J Dermatol 2002; 147: 324-30.

22. Patel AN, Langan SM, Batchelor JM. A randomized trial of methotrexate vs. azathioprine for severe atopic eczema: a critical appraisal. Br J Dermatol 2012; 166: 701-4.

23. Roekevisch E, Spuls PI, Keuster D, et al. Efficacy and safety of systemic treatments for moderate-to-severe atopic dermatitis: a systemic review. J Allergy Clin Immunol 2014; 133: 429-38.

24. Murphy LA, Atherton D. A retrospective evaluation of azathioprine in severe childhood atopic eczema using thiopurine methyltransferase levels to exclude patients at high risk myelosuppression. Br J Dermatol 2002; 147: 308-15.

25. Caufield M, Tom WL. Oral azathiopryne for recalcitrant pediatric atopic dermatitis: clinical response and thiopurine monitoring. I Am Acad Dermatol 2013; 68: 29-35.

26. Hon KL, Ching GK, Leung TF, et al. Efficacy and tolerability at 3 and 6 months following use of azathiopryne for recalcitrant atopic dermatitis in children and young adults. J Dermatol Treat 2009; 20: 141-5.

27. He A, Feldman SR, Fleischer AB Jr. An assessment of the use of antihistamines in the management of atopic dermatitis. J Am Acad Dermatol 2018; 79: 92-6. 
28. Czarnecka-Operacz M, Silny W. Specific immunotherapy in atopic dermatitis. Acta Dermatovenerol Croat 2006; 14: 52-9.

29.Jutel M, Solarewicz-Madejek K, Węgrzyn A. Allergen-specific immunotheraphy in atopic dermatitis. Adv Dermatol Allergol 2011; 28: 389-95.

30. Silny W, Czamecka-Operacz M. Spezifische Immuntherapie bei der Behandlung von Patienten mit atopischer Dennatitis. Ergeb-nisse einer placebokontrollierten Doppelblindstudie. Allergologie 2006; 29: 171-83.

31. Silny W, Jenerowicz D. Immunoterapia swoista. In: Atopowe zapalenie skóry. Silny W (ed.). Termedia, Poznań 2012; 271-8.

32. Kim SO, Ah YM, Yu YM, et al. Effects of probiotics for the treatment of atopic dermatitis: a meta-analysis of randomized controlled trials. Ann Allergy Asthma Immunol 2014; 113 217-26.

33. Lee J, Seto D, Bielory L. Meta-analysis of clinical trials of probiotics for prevention and treatment of pediatric atopic dermatitis. J Allergy Clin Immunol 2008; 121: 116e.

34. Li L, Han Z, Niu X, et al. Probiotic supplementation for prevention of atopic dermatitis in infants and children: a systematic review and meta-analysis. Am J Clin Dermatol 2019; 20: 367-77.

35. Folster-Holst R, Müller F, Schnopp N, et al. Prospective, randomized controlled trial on Lactobacillus rhamnosus in infants with moderate tosevere atopic dermatitis. Br I Dermatol 2006; 155: 1256-61.

36. Cuello-Garcia CA, Brożek JL, Fiocchi A, et al. Probiotics for the prevention of allergy: a systematic review and meta-analysis of randomized controlled trials. J Allergy Clin Immunol 2015; 136: 952-61.

37. Farina S, Gisondi P, Zanoni M, et al. Balneotherapy for atopic dermatitis in children at Comano spa in Trentino, Italy. J Dermatolog Treat 2011; 22: 366-71.

38. Lee MS, Choi J, Posadzki P, Ernst E. Aromatherapy for health care: an overview of systematic reviews. Maturitas 2012; 71: 257-60.

39. Posadzki P, Alotaibi A, Ernst E. Adverse effects of aromatherapy: a systematic review of case reports and case series. Int J Risk Saf Med 2012; 24: 147-61.

40.Vestergaard C, Wollenberg A, Barbarot S, et al. European task force on atopic dermatitis position paper: treatment of parental atopic dermatitis during preconception, pregnancy and lactation period. J Eur Acad Dermatol Venereol 2019; 33: 1644-59.

41. Paller AS, Tom WL, Lebwohl MG, et al. Efficacy and safety of crisaborole ointment, a novel, nonsteroidal phosphodiesterase 4 (PDE4) inhibitor for the topical treatment of atopic dermatitis (AD) in children and adults. J Am Acad Dermatol 2016; 75: 494-503.

42. Eichenfield LF, Call RS, Forsha DW, et al. Long-term safety of crisaborole ointment $2 \%$ in children and adults with mild to moderate atopic dermatitis. J Am Acad Dermatol 2017; 77: 641-9.

43.Zhong CS, Elmariah SB. Novel therapies in the treatment of atopic dermatitis. Semin Cutan Med Surg 2018; 37: 190-7.

44.Hon KL, Leung AKC, Leung TNH, Lee VWY. Investigational drugs for atopic dermatitis. Expert Opin Investig Drugs 2018; 27: 637-47.

45. Chiricozzi A, Peroni D, Girolomoni G. Testing biologics and intracellular signaling inhibitors on pediatric atopic dermatitis: a stairway to modern therapeutic approaches. Expert Opin Investig Drugs 2018; 27: 699-707.
46. Edwards T, Patel NU, Blake A, et al. Insights into future therapeutics for atopic dermatitis. Expert Opin Pharm 2018; 19 : 265-78.

47. Thijs JL, Strickland I, Bruijnzeel-Koomen CA, et al. Moving toward endotypes in atopic dermatitis: Identification of patient clusters based on serum biomarker analysis. J Allergy Clin Immunol 2017; 140: 730-7. 